\title{
Remodelling a shp: Transmetallation in a Rare-Earth Cluster-based Metal-Organic Framework
}

\author{
Hudson A. Bicalho ab, P. Rafael Donnarumma ${ }^{\text {ab }}$, Victor Quezada-Novoa ${ }^{\text {ab }}$, Hatem M. Titic, Ashlee J. Howarth ${ }^{\text {ab* }}$ \\ ${ }^{a}$ Department of Chemistry and Biochemistry, Concordia University, 7141 Sherbrooke St W., Montréal, QC, Canada \\ ${ }^{b}$ Centre for NanoScience Research, Concordia University, Montréal, QC, Canada \\ ${ }^{c}$ Department of Chemistry, McGill University, 801 Sherbrooke St W., Montréal, QC, Canada
}

KEYWORDS: MOFs, rare-earth element, transmetalation, post-synthetic modification, metal-exchange

\begin{abstract}
Post-synthetic modification (PSM) of metal-organic frameworks (MOFs) is an important strategy for accessing MOF analogues that cannot be easily synthesized de novo. In this work, the rare-earth (RE) cluster-based MOF, Y-CU-10, with shp topology was modified through transmetallation using a series of RE ions, including: $\mathrm{La}(\mathrm{III}), \mathrm{Nd}(\mathrm{III}), \mathrm{Eu}(\mathrm{III}), \mathrm{Tb}(\mathrm{III})$, Er(III), Tm(III), and Yb(III). In all cases, metal-exchange higher than $70 \%$ was observed, with reproducible results. All transmetallated materials were fully characterized and compared to the parent MOF, Y-CU-10, in regards to crystallinity, surface area, and morphology. Additionally, single-crystal X-ray diffraction (SCXRD) measurements were performed to provide further evidence of transmetallation occurring in the nonanuclear cluster nodes of the MOF.
\end{abstract}

\section{Introduction}

Metal-organic frameworks (MOFs) are a family of structurally diverse and porous materials comprised of concatenated organic building blocks, known as linkers, and inorganic building units extending in 2- or 3-dimensions. ${ }^{1-6}$ The rapid development of MOFs in the past few decades has spawned a myriad of materials with varied architectures and functionalities. ${ }^{7}$ Due to their chemical and physical properties, MOFs have potential applications in several fields including, but not limited to, catalysis, ${ }^{8-11}$ gas adsorption and storage, ${ }^{12-14}$ chemical sensing, ${ }^{15,16}$ and light harvesting. ${ }^{17}$

MOFs can be designed de novo through the use of reticular chemistry. ${ }^{18}$ After selecting the appropriate metal nodes and organic linkers to give a desired topology, synthetic conditions must then be controlled to facilitate metal-ligand bonding with suitable geometry and connectivity. Nonetheless, it can be challenging to control reaction conditions to obtain a desired topology, since many metal and organic precursor combinations can give rise to multiple possible topologies. ${ }^{19}$ One way to circumvent this challenge and to avoid rigorous synthetic optimization, is through the use of post-synthetic modification (PSM) strategies. ${ }^{20}$ PSM is a group of methodologies that involves the modification of parent MOFs into novel daughter frameworks exhibiting different, and sometimes enhanced, properties compared to their predecessors. ${ }^{21,22}$ There are several different types of PSM methods, which include modifying the MOF linker, node, or encapsulating guests inside the framework. Linkerbased PSM in MOFs includes (i) linker modification (i.e., covalent PSM), where the linker in the structure is chemically modified while still part of the MOF, ${ }^{23,24}$ (ii) linker exchange (i.e., solvent assisted linker exchange (SALE), ${ }^{25}$ or post-synthetic exchange (PSE) ${ }^{26}$ ), in which a linker is exchanged for a different one, or (iii) post-synthetic annealing (PSA), where linkers and capping ligands in a MOF are rearranged..$^{27}$ On the other hand, metal-based PSM of MOFs includes (i) transmetallation, where the metal is replaced with a new metal that can adopt the same coordination number and geometry, ${ }^{28,29}$ (ii) atomic layer deposition in a MOF (AIM) where metal ions/clusters are deposited on a MOF metal node, ${ }^{30,31}$ or (iii) solvent assisted metal insertion (SAMI), where metal ions are post-synthetically coordinated to a MOF metal node. ${ }^{32,33}$ Transmetallation, in particular, is one strategy that can be used to access MOF analogues that are difficult to synthesize de novo. The partial or complete substitution of a metal in a MOF, through transmetallation, has the potential to lead to a daughter material with new properties such as enhanced catalytic activity or adsorption. In general, the degree of transmetallation in a MOF will be governed by a series of factors, including the lability of the M-L bond, the ionic radii of the incoming vs. outgoing metal ion, the preferred coordination number and geometries of the incoming and outgoing metal ion, the solvent used, and the chemical stability of the parent and daughter MOFs. ${ }^{34}$

Rare-earth (RE) elements, which include Y, Sc and the 15 $f$-block lanthanoids, are a group of metals that share similar chemistry and are therefore expected to behave similarly in regards to MOF synthesis and structure. ${ }^{35}$ However, de novo synthesis of isostructural RE-MOFs comprised of each of the $17 \mathrm{RE}$ elements can be challenging due to the variability in 
ionic radii and preferred coordination number of these ions. ${ }^{36}$ De novo synthesis can be particularly challenging when constructing RE-MOFs with high nuclearity clusterbased nodes, since the lability and thus stability of the REclusters vary with ionic radii. For this reason, PSM, specifically transmetallation, is attractive for the synthesis of new RE-MOFs not easily attainable de novo. In that sense, transmetallation is an effective way of incorporating or completely substituting new RE ions into a parent MOF, be it via metal (non-RE) to $\mathrm{RE}$ ion, ${ }^{37-39}$ or $\mathrm{RE}$ to $\mathrm{RE}$ ion exchange. ${ }^{40-42}$ However, to this date, only a few examples of transmetallation in RE-MOFs have been shown in the literature, ${ }^{40-42}$ and to the best of our knowledge, none involve RE-cluster based MOFs.

Herein, we report the transmetallation of Y(III) ions for other RE(III) ions (RE(III) = La(III), Nd(III), Eu(III), Tb(III), Er(III), Tm(III), and Yb(III)) in Y-CU-10. This MOF is comprised of nonanuclear cluster nodes bridged by tetratopic pyrene-based linkers, giving rise to a framework with shp topology (Figure 1). Attempts to synthesize RE-CU-10 analogues $(\mathrm{RE}(\mathrm{III})=\mathrm{La}(\mathrm{III}), \mathrm{Nd}(\mathrm{III}), \mathrm{Eu}(\mathrm{III}), \mathrm{Tb}(\mathrm{III}), \mathrm{Er}(\mathrm{III})$, $\mathrm{Tm}(\mathrm{III})$, and $\mathrm{Yb}(\mathrm{III})$ ) de novo through the direct translation of synthetic conditions for Y-CU-10 (i.e., simply using the same molar ratio of metal ion precursor) have been unsuccessful. Indeed, a recent report on the synthesis of Eu-CU10/PCN-502(Eu) demonstrates that synthetic conditions are quite different than those used for Y-CU-10.43 As such, the results shine light on transmetallation as a viable approach for obtaining difficult-to-synthesize RE-MOF analogues. The daughter MOFs are fully characterized, demonstrating a high degree of transmetallation, while maintaining the expected network structure. Furthermore, single crystal X-ray diffraction (SCXRD) of the transmetallated Tm-CU-10 analogue demonstrates that the incoming Tm(III) ion is incorporated into the nonanuclear cluster node of the MOF.

\section{Experimental Section}

\subsection{Materials}

All chemicals were used as received. $N, N^{\prime}$-dimethylformamide (DMF), acetone, methanol, nitric acid, hydrogen peroxide (30\%, w/w) and glacial acetic acid (HAc) were purchased from Fisher Scientific. 2-fluorobenzoic acid, yttrium(III) nitrate hexahydrate $\left[\mathrm{Y}\left(\mathrm{NO}_{3}\right)_{3} .6 \mathrm{H}_{2} \mathrm{O}\right]$, lanthanum(III) nitrate hexahydrate $\left[\mathrm{La}\left(\mathrm{NO}_{3}\right)_{3} .6 \mathrm{H}_{2} \mathrm{O}\right]$, neodymium(III) nitrate hydrate $\left[\mathrm{Nd}\left(\mathrm{NO}_{3}\right)_{3} \cdot \mathrm{xH}_{2} \mathrm{O}\right]$, europium(III) nitrate hexahydrate $\left[\mathrm{Eu}\left(\mathrm{NO}_{3}\right)_{3} .6 \mathrm{H}_{2} \mathrm{O}\right]$, terbium(III) nitrate hydrate $\left[\mathrm{Tb}\left(\mathrm{NO}_{3}\right)_{3} . \mathrm{xH}_{2} \mathrm{O}\right]$, erbium(III) nitrate hydrate [Er( $\left.\left(\mathrm{NO}_{3}\right)_{3} \cdot \mathrm{xH}_{2} \mathrm{O}\right]$, thulium(III) nitrate hydrate $\left[\mathrm{Tm}\left(\mathrm{NO}_{3}\right)_{3} \cdot \mathrm{xH}_{2} \mathrm{O}\right]$, and ytterbium nitrate hydrate $\left[\mathrm{Yb}\left(\mathrm{NO}_{3}\right)_{3} . \mathrm{xH}_{2} \mathrm{O}\right]$ were purchased from Alfa Aesar.

\subsection{Synthesis of Y-CU-10}

The 4,4',4",4"'-(pyrene-1,3,6,8-tetrayl)tetrabenzoic acid ( $\mathrm{H}_{4}$ TBAPy) linker was synthesized following a reported procedure. $^{44}$ In a typical synthesis of Y-CU-10,45 $\mathrm{Y}\left(\mathrm{NO}_{3}\right)_{3} .6 \mathrm{H}_{2} \mathrm{O}$ (249.3 mg, $\left.0.652 \mathrm{mmol}\right), \mathrm{H}_{4} \mathrm{TBAPy}(111.0 \mathrm{mg}$, $0.163 \mathrm{mmol}$ ), and 2-fluorobenzoic acid (4560.6 mg, 32.5 mmol) were mixed with $28.3 \mathrm{~mL}$ of DMF, $2.3 \mathrm{~mL}(130$ $\mathrm{mmol}$ ) of deionized water and $6.1 \mathrm{~mL}$ (106 mmol) of HAc.

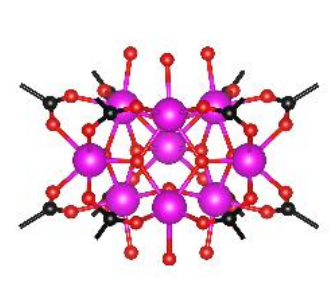

$$
\mathrm{RE}_{9} \text { cluster }
$$

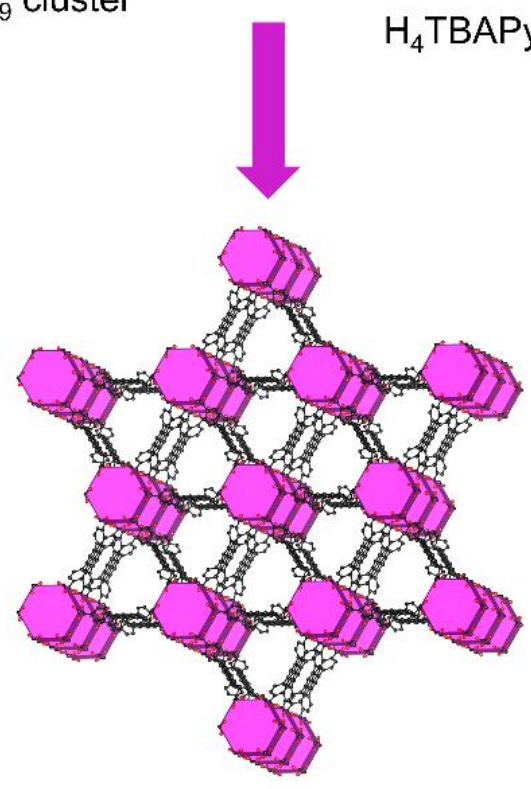

RE-CU-10 MOF

Figure. 1. Structure of RE-CU-10, showing the nonanuclear RE-cluster node and $\mathrm{H}_{4}$ TBAPy linker.

This suspension was homogenized by sonication for 10 minutes and then equally transferred to three 8-dram vials, which were placed in a preheated oven at $120{ }^{\circ} \mathrm{C}$ for $48 \mathrm{~h}$. The obtained yellow crystals were separated via centrifugation and washed three times with fresh DMF over the course of $24 \mathrm{~h}$. Solvent exchange was conducted by replacing DMF and washing the MOF three times with fresh acetone over the course of $24 \mathrm{~h}$. Finally, the material was air dried and activated at $120^{\circ} \mathrm{C}$ for $12 \mathrm{~h}$ under vacuum.

\subsection{Transmetallation of Y-CU-10}

In the optimized transmetallation procedure, $2.75 \mathrm{mmol}$ of Y-CU-10 (10 mg, $24.76 \mathrm{mmol}$ of $\mathrm{Y}$ ) was added to $5 \mathrm{~mL}$ of a DMF solution containing 5 eqv. (123.8 mmol) of the $\mathrm{RE}\left(\mathrm{NO}_{3}\right)_{3} \cdot \mathrm{xH}_{2} \mathrm{O}$ salt $(\mathrm{RE}=\mathrm{La}, \mathrm{Nd}, \mathrm{Eu}, \mathrm{Tb}, \mathrm{Er}, \mathrm{Tm}, \mathrm{Yb})$. The reaction mixture was then placed in a preheated oven at 140 ${ }^{\circ} \mathrm{C}$ for 14 days. After 3,7 and 11 days, the material was collected and washed three times with fresh DMF, and the $\mathrm{RE}\left(\mathrm{NO}_{3}\right)_{3} \cdot \mathrm{xH}_{2} \mathrm{O}$ salt solution was replaced by a new one (123.8 $\mathrm{mmol}$ in $5 \mathrm{~mL}$ of DMF). The obtained materials were washed three times with DMF over the course of 24 hours, followed by washing with fresh acetone over the course of 24 hours. The materials were air dried and activated at 120 o $\mathrm{C}$ for $12 \mathrm{~h}$ under vacuum. The degree of transmetallation was measured by inductively coupled plasma mass spectrometry (ICP-MS). For comparison purposes, all 
transmetallation reactions were performed in quadruplicates.

\subsection{Characterization}

Powder X-ray diffraction patterns were recorded using a Bruker D2 Phaser diffractometer with $\mathrm{CuK \alpha}$ irradiation $(\lambda=$ $1.54178 \AA$ ) equipped with a LYNXEYE linear position sensitive detector (Bruker AXS, Madison, WI) over a range of $4^{\circ}$ $<2 \theta<20^{\circ}$ at a scan rate of $6^{\circ} \mathrm{min}^{-1}$. Brunauer-EmmettTeller (BET) specific surface area measurements were determined by $\mathrm{N}_{2}$ adsorption-desorption isotherms collected at $77 \mathrm{~K}$ on a Micromeritics TriStar II Plus instrument. Prior to the analysis, the samples were subject to washing and solvent exchange with DMF followed by acetone, and then activated at $120{ }^{\circ} \mathrm{C}$ for $12 \mathrm{~h}$ using a Micromeritics Smart VacPrep instrument equipped with a hybrid turbo vacuum pump. Scanning electron microscopy (SEM) images and energy-dispersive X-ray (EDX) spectroscopy were recorded on a Phenom ProX Desktop SEM instrument. ICP-MS measurements were carried out using a 7500 Agilent 7500ce equipment. Prior to the analysis, $0.5-1.0 \mathrm{mg}$ of MOF sample was added to $0.8 \mathrm{~mL}$ of concentrated $\mathrm{HNO}_{3}$ and heated at $100{ }^{\circ} \mathrm{C}$ for $1 \mathrm{~h}$ in a sand bath. Then, after cooling down to room temperature, $0.2 \mathrm{~mL}$ of $\mathrm{H}_{2} \mathrm{O}_{2}(30 \%$, w/w) was added to the mixture and heated at $100{ }^{\circ} \mathrm{C}$ for another $2 \mathrm{~h}$. Finally, the samples were sonicated for 30 minutes or until complete solubilization. The volumes of the digested samples were first adjusted to $10 \mathrm{~mL}$ using MilliQ water, and then further diluted 30 times. Crystals of transmetallated TmCU-10 were coated with a thin layer of amorphous oil and mounted on single crystal X-ray diffraction (SCXRD) at room temperature. Data were measured on a Bruker D8 Venture diffractometer equipped with a Photon 200 area detector, and $I \mu S$ microfocus X-ray source (Bruker AXS, $\mathrm{CuK \alpha}$ source).

\section{Results and Discussion}

Y-CU-10 is one of a handful of RE-MOFs found in the literature comprised of a highly connected, high nuclearity ( $>6$ ions) cluster node. ${ }^{46-49}$ Owing to the high chemical and thermal stability of Y-CU-10, as well as the $12 \AA$ channels, our group recently demonstrated that Y-CU-10 is a highly effective catalyst for the oxidative detoxification of a sulfur mustard simulant via the production of singlet oxygen $\left({ }^{1} \mathrm{O}_{2}\right){ }^{45}$ Furthermore, by substituting Y(III) for heavier rare-earth metals, such as $\mathrm{Tb}(\mathrm{III})$, enhanced catalytic activity is observed. However, the synthesis of RE-CU-10 analogues has been challenging, as the synthetic procedure cannot be directly translated from that developed for Y-CU-10, resulting in a series of issues related to phase impurities (Figure S1), and low yields. Thus, in an attempt to access additional RE analogues of Y-CU-10, we performed metal-exchange (i.e., transmetallation) of the Y(III) ions using other RE(III) precursors (RE(III) = La(III), Nd(III), Eu(III), Tb(III), Er(III), $\mathrm{Tm}(\mathrm{III})$, and $\mathrm{Yb}(\mathrm{III})$ ), to yield a series of RE-CU-10 analogues, most of which could not be obtained de novo.

To determine if transmetallation could be performed on Y-CU-10, methanol and DMF were screened as reaction solvents at 60 and $120^{\circ} \mathrm{C}$, respectively (Figure S2, Table S1). While metal-exchange in the presence of methanol has shown promising results in previous works, ${ }^{50,51}$ DMF can

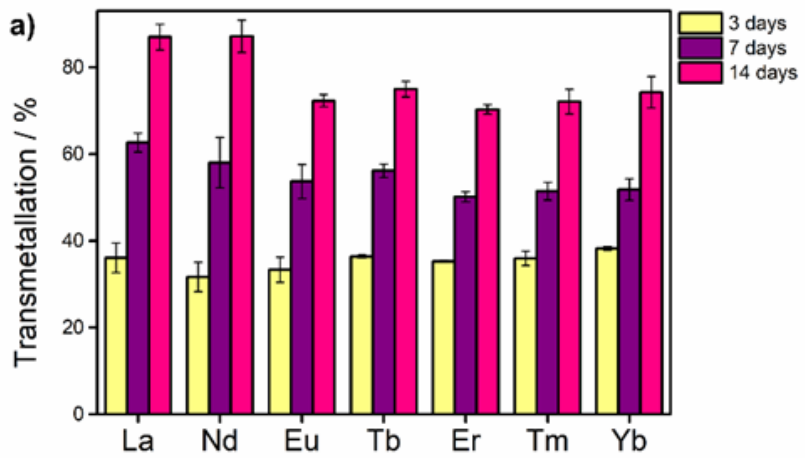

b)

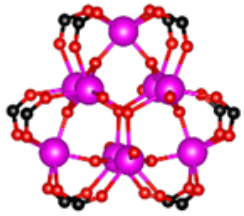

$\mathrm{Y}_{9}$ cluster

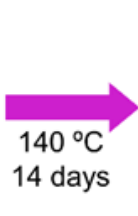

Transmetallated $\mathrm{RE}_{9}$ cluster

$\mathrm{RE}=\mathrm{La}, \mathrm{Nd}, \mathrm{Eu}, \mathrm{Tb}$ $\mathrm{Er}, \mathrm{Tm}, \mathrm{Yb}$
Figure 2. a) The degree of transmetallation in Y-CU-10 when using eight different RE(III) precursors and b) the nonanuclear cluster of CU-10 before and after the transmetallation experiments (pink spheres = Y(III); green spheres $=$ RE(III)).

be heated at higher temperatures (boiling point: $64.7 \mathrm{vs}$. $153{ }^{\circ} \mathrm{C}$, respectively) and has also proven to be an effective solvent for transmetallation. ${ }^{52,53}$

After 7 days of reaction in methanol at $60{ }^{\circ} \mathrm{C}$ using 5 equivalents of RE(III) precursor, approximately $5 \%$ and $7 \%$ of the Y(III) ions of Y-CU-10 were exchanged by Eu(III) or $\mathrm{Tb}(\mathrm{III})$, respectively. On the other hand, when DMF was used as a reaction solvent at $120{ }^{\circ} \mathrm{C}$ using the same molar ratio of RE(III) ion precursor, exchange of $14 \%$ (Eu) and 15 $\%(\mathrm{~Tb})$ of the Y(III) ions in Y-CU-10 was observed after only 3 days of reaction. These preliminary results indicate that higher temperature enhances the transmetallation process in Y-CU-10. Additional attempts at optimizing the degree of transmetallation were carried out by increasing the reaction temperature in DMF from 120 to $140{ }^{\circ} \mathrm{C}$, as well as the amount of RE(III) precursor from 5 to 10 equivalents (Figure S3, Table S2). Not surprisingly, both increasing the RE(III) precursor concentration and increasing the temperature to $140{ }^{\circ} \mathrm{C}$ were found to enhance the transmetallation efficiency in Y-CU-10. For example, after 7 days of reaction in DMF using 10 equivalents of RE(III) precursor, transmetallation of $\mathrm{Tb}$ (III) was enhanced from 22 to $60 \%$ while that of Eu(III) was enhanced from 29 to $58 \%$, when changing the temperature from 120 to $140 \stackrel{\circ}{\circ}$. Furthermore, by increasing the reaction time at $140^{\circ} \mathrm{C}$ in DMF to 14 days, and the amount of RE(III) precursor from 10 to 15 equivalents (Figure S4, Table S3), exchange as high as $91 \%$ for $\mathrm{Eu}(\mathrm{III})$ was observed. These results demonstrate that near complete transmetallation of the Y(III) ions in Y-CU-10 with other RE(III) ions is possible. 
Given that some $\mathrm{RE}\left(\mathrm{NO}_{3}\right)_{3} \cdot \mathrm{xH}_{2} \mathrm{O}$ precursors are expensive, and that even partial substitution of the Y(III) ions with $\mathrm{RE}(\mathrm{III})$ ions is expected to endow the daughter framework with new properties, we sought to optimize the transmetallation process to obtain the highest exchange efficiency possible while minimizing the use of RE(III) precursors. As such, the degree of transmetallation in Y-CU-10 with several RE(III) ions was evaluated using 5 equivalents of RE(III) precursor in DMF at $140{ }^{\circ} \mathrm{C}$ for 3,7 and 14 days (Figure $2 \mathrm{a}$, Table S4). After 14 days, the metal exchange in Y-CU-10 was found to be higher than $70 \%$ when using seven rare-earth metals: La(III), Nd(III), Eu(III), Tb(III), Er(III), Tm(III), and $\mathrm{Yb}(\mathrm{III})$. Furthermore, these experiments were completed in quadruplicates and the amount of Y(III) exchanged was found to be highly reproducible. Ultimately, these results indicate that 6 or more of the 9 Y(III) ions in the metal cluster node of Y-CU-10 can be exchanged under these conditions optimized for a balance of cost and efficiency (Figure $2 \mathrm{~b}$ ).

To confirm the structural integrity of the post-synthetically modified RE-CU-10 analogues, PXRD was performed. Upon close inspection of the reflections found in the patterns pre- and post-transmetallation, it can be stated that the bulk of the material remains structurally the same, as no considerable changes in the diffraction patterns were observed (Figure 3). Nonetheless, the crystallinity of the daughter RE-CU-10 analogues varies as a function of RE(III) ion (Figure S5). Since there is no evidence of new crystalline phases being formed, this variation in crystallinity can be attributed to a partial amorphization of the material. Interestingly, the crystallinity of the daughter RE-CU-10 analogues is clearly associated with the ionic radii of the RE(III) used, where an increase in iodic radius - towards the lighter lanthanoids - seems to

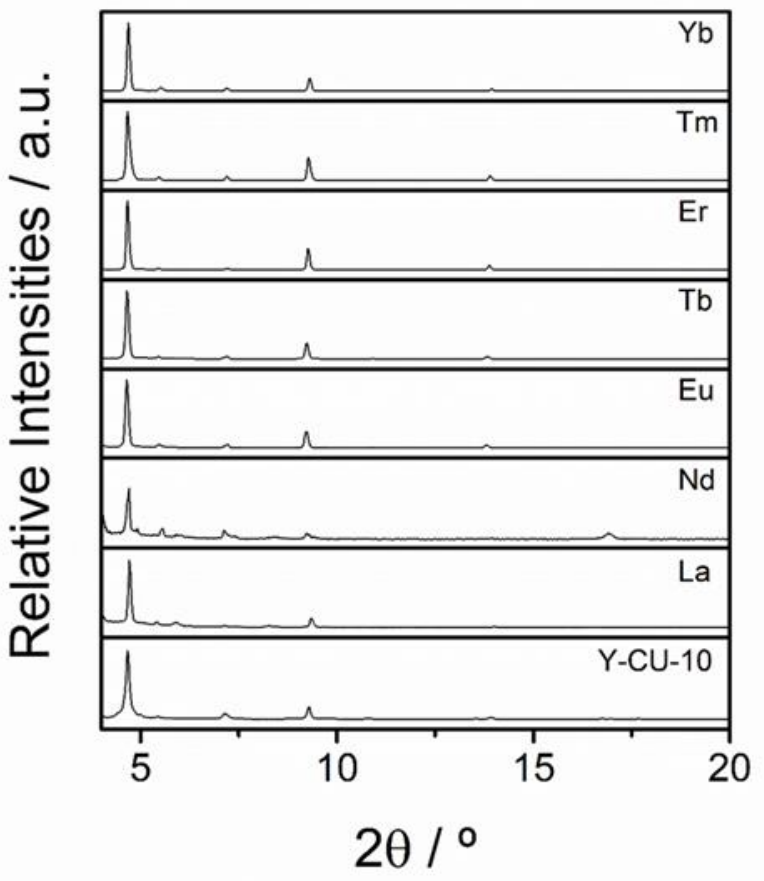

Figure. 3. Normalized PXRD patterns of Y-CU-10, as well as the MOF after metal exchange with La(III), Nd(III), Eu(III), $\mathrm{Tb}(\mathrm{III}), \operatorname{Er}(\mathrm{III}), \mathrm{Tm}(\mathrm{III})$, and Yb(III).

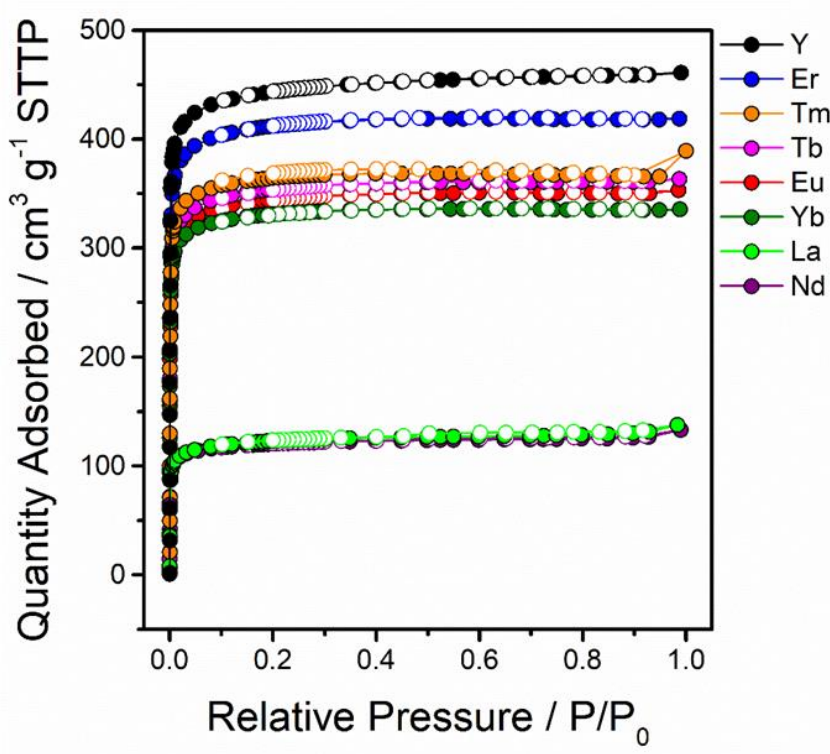

Figure. 4. $\mathrm{N}_{2}$ sorption isotherms of $\mathrm{Y}-\mathrm{CU}-10$ and the transmetallated RE-CU-10 analogues.

weaken the structure and lead to a greater decrease in bulk crystallinity of the material. It is well-known that carboxylates of larger RE(III) ions prefer higher coordination numbers (CNs), so when Y(III) ( $\mathrm{CN}=8$ ) is replaced with lanthanoids from $\mathrm{La}(\mathrm{III})$ to $\mathrm{Nd}(\mathrm{III})$ (preferred $\mathrm{CN}=9$ ) these ions are less likely to adapt to the lower coordination number environment. ${ }^{4}$ It is possible that when trying accommodate a $\mathrm{CN}$ of 9 in these larger ions, there are steric issues that lead to instability of the nonanuclear cluster, resulting in partial amorphization of the material. This hypothesis is further supported by studying the crystallinity of Y-CU-10 exchanged with La(III). After 3 days reaction, the transmetallation rate follows the same trend as that observed for the other RE metals, where approximately 3 of the 9 Y(III) ions of the cluster are exchanged, and only a small decrease in the bulk crystallinity is observed (Figure 2a, Figure S6). Whereas after 7 days, approximately 6 of the 9 Y(III) ions are exchanged, accounting for a more marked decrease in bulk crystallinity. Finally, after 14 days, approximately 8 of the 9 Y(III) ions in the cluster are exchanged for La(III), a clear deviation ( $>10 \%$ ) in comparison with the heavier lanthanoids, and the crystallinity of the material has greatly decreased. This suggests there is a threshold in the percentage of Y(III) ( $\mathrm{CN}=8)$ that can be exchanged with larger lanthanoids (preferred $\mathrm{CN}=9$ ) in the nonanuclear cluster before the system collapses.

To evaluate the effects of transmetallation on the surface area of CU-10, nitrogen sorption isotherms were collected and used to calculate BET surface areas. As can be seen in Figure 4, all materials display the expected reversible TypeI(a) isotherm. ${ }^{55}$ While the parent MOF, Y-CU-10, displays a BET surface area of $1790 \mathrm{~m}^{2} \mathrm{~g}^{-1}$, a slight decrease in surface area is observed for the heavier lanthanoids: $\mathrm{Eu}\left(1400 \mathrm{~m}^{2} \mathrm{~g}\right.$ $\left.{ }^{1}\right)$, $\operatorname{Tb}\left(1470 \mathrm{~m}^{2} \mathrm{~g}^{-1}\right), \operatorname{Er}\left(1720 \mathrm{~m}^{2} \mathrm{~g}^{-1}\right), \operatorname{Tm}\left(1520 \mathrm{~m}^{2} \mathrm{~g}^{-1}\right)$, and $\mathrm{Yb}\left(1360 \mathrm{~m}^{2} \mathrm{~g}^{-1}\right)$. The surface areas of these 

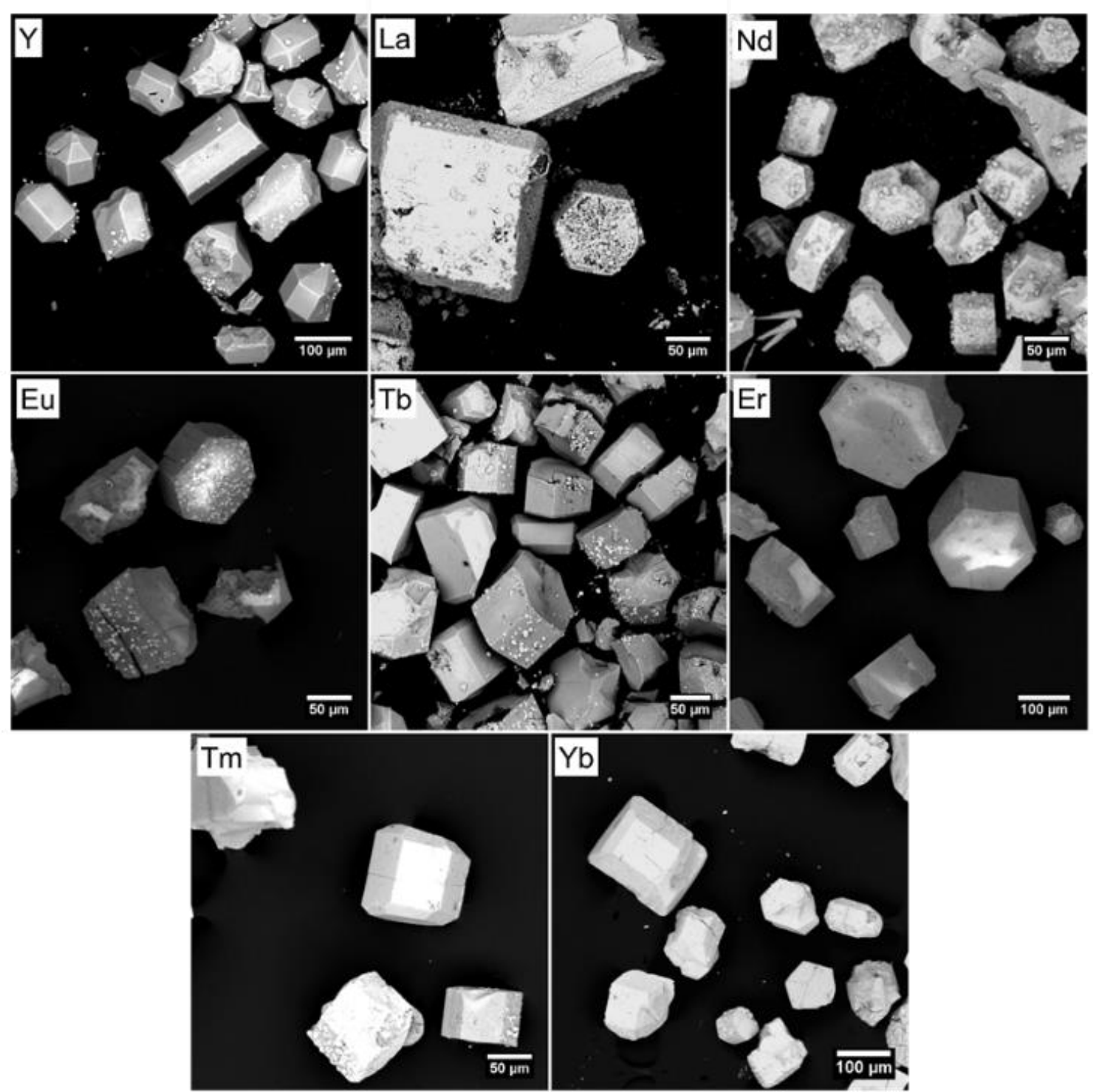

Figure. 5. SEM micrographs of the parent Y-CU-10 and the metal-exchanged MOFs.

daughter RE-CU-10 analogues are decreased compared to the parent MOF due to the presence of heavier RE(III) ions, the use of activation procedures that were optimized for YCU-10 only, and in the case of Eu(III) and Tb(III) a small degree of amorphization of the material. On the other hand, the early lanthanoids, La and Nd, demonstrated a steep drop in surface area: La $\left(480 \mathrm{~m}^{2} \mathrm{~g}^{-1}\right)$ and $\mathrm{Nd}\left(475 \mathrm{~m}^{2} \mathrm{~g}^{-1}\right)$, consistent with the observed decrease in crystallinity and partial amorphization of these CU-10 analogues.

In order to obtain a more complete understanding of the location of the new RE(III) ions exchanged in Y-CU-10, SEM micrographs coupled with EDS data were obtained. As shown in Figure 5, crystals with hexagonal prismatic shapes consistent with the shp topology are observed for Y-CU-10 and for all transmetallated MOFs. However, the Y-CU-10 analogues exchanged with early lanthanoids (i.e., La(III), and $\mathrm{Nd}(\mathrm{III})$ ) clearly show a rough surface, possibly indicating the formation of structural defects. Consistent with PXRD and nitrogen sorption data, the surface roughness of these materials increases with increasing ionic radii of the incoming RE(III) ion. On the other hand, the transmetallated samples containing Er(III), Tm(III), and Yb(III) have welldefined hexagonal morphology, nearly identical to the parent Y-CU-10. Additionally, EDS line scan analysis was performed on single crystallites of all transmetallated samples (Figures S7-S13). In all cases, homogeneous distributions of the lanthanoids and $Y$ could be observed, indicating that the metal-exchange process is indeed taking place throughout the framework, rather than on the external surface only.

Finally, to unequivocally confirm that RE(III) ions are being introduced into the nonanuclear cluster of Y-CU-10, single crystal X-ray diffraction was performed on a single crystal of the transmetallated Tm(III) analogue (Table S5). Our group, and others have shown that the nonanuclear cluster node in Y-CU-10, Tb-CU-10 and other RE(III)-shp-MOFs is disordered over two positions. ${ }^{45,56}$ SCXRD performed on the transmetallated Tm(III) analogue shows that, in both nonanuclear clusters, 6 of the 9 Y(III) ions are replaced with Tm(III). When analyzing the double six membered ring (d6r) building unit of CU-10 (Figure 6), the top and bottom 
rings are comprised of Tm(III) ions, while the middle layer is comprised of Y(III). This result is consistent with the $\sim 70$ $\%$ exchange determined using ICP-MS.

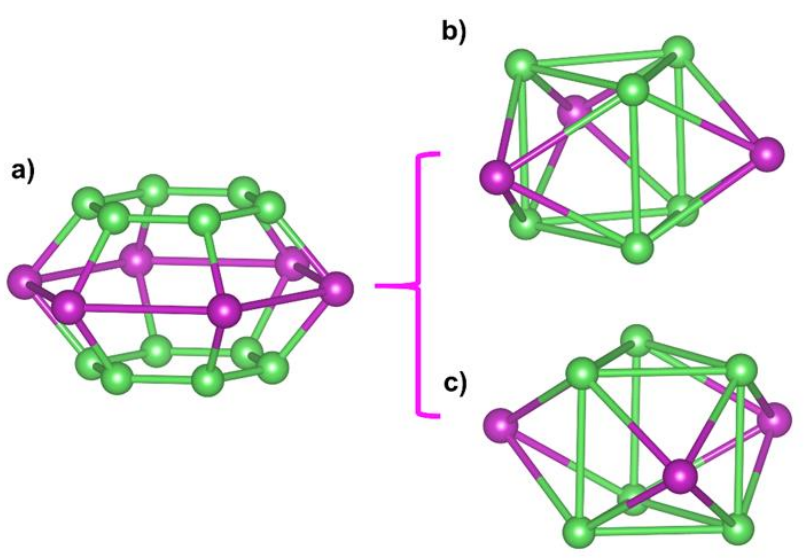

Figure. 6. Representation of (a) the transmetallated disordered RE9 cluster (appearing as a $\mathrm{RE}_{18}$ cluster), and separated into nonanuclear building units: (b) and (c).

\section{Conclusions}

In summary, post-synthetic modification of Y-CU-10 was performed by transmetallation of Y(III) using seven different RE ions: La(III), Nd(III), Eu(III), Tb(III), Er(III), Tm(III), and $\mathrm{Yb}(\mathrm{III})$. By optimizing the reaction conditions for cost and efficiency, all seven daughter MOFs displayed transmetallation rates higher than $70 \%$. Characterization of the daughter materials indicates that the overall network structure of CU-10 is maintained after the transmetallation process. However, the metal-exchanged La- and Nd-CU-10 analogues clearly demonstrate a higher degree of amorphization of the structure, which can be attributed to their higher ionic radii and different coordination number preferences, compared to the other RE(III) ions. Finally, SCXRD measurements on transmetallated Tm-CU-10 confirmed that the Y(III) ions were replaced by Tm(III) in the nonanuclear clusters of the MOF with a ratio of Y:Tm of 3:6, matching the results obtained by ICP-MS. These results shine light on the use of transmetallation in RE cluster-based MOFs, something that has not been explored in the literature before. The example here shows that by simply adjusting the reaction parameters, partial or near-complete transmetallation can be accomplished, with the potential to give new RE-MOF analogues with unique properties and applications.

\section{ASSOCIATED CONTENT}

All transmetallation data, SEM-EDS micrographs, raw ICP-MS data and calculations, and single-crystal X-ray diffraction data are provided. The crystal structure of Tm-CU-10 was deposited in the Cambridge Crystallographic Data Centre (CCDC), deposition number 2079223.

\section{AUTHOR INFORMATION}

Corresponding Author

*ashlee.howarth@concordia.ca

Tel. +1 (514) 848-2424 ext. 5324

Author Contributions

All authors have given approval to the final version of the manuscript.

\section{Notes}

The authors declare no competing financial interest.

\section{ACKNOWLEDGMENT}

H.A.B thanks Concordia University for the Concordia University Graduate Fellowship and Concordia International Tuition Award of Excellence scholarships. The authors gratefully acknowledge the members of the Howarth and Majewski research groups for offering a supportive research environment. We are grateful to Prof. Tomislav Friščić for providing access to $\mathrm{X}$-ray diffraction instrumentation, and to Dr. Heng Jiang from Concordia's Centre for Biological Applications of Mass Spectrometry for ICP-MS analysis. We acknowledge the support of the Natural Sciences and Engineering Research Council of Canada (NSERC), [funding reference number: DGECR-201800344]. Cette recherche a été financée par le Conseil de recherches en sciences naturelles et en génie du Canada (CRSNG), [numéro de reference: DGECR-2018-00344].

\section{REFERENCES}

(1) Batten, S. R.; Champness, N. R.; Chen, X. M.; Garcia-Martinez, J.; Kitagawa, S.; Öhrström, L.; O’Keeffe, M.; Suh, M. P.; Reedijk, J. Terminology of Metal-Organic Frameworks and Coordination Polymers (IUPAC Recommendations 2013). Pure Appl. Chem. 2013, 85 (8), 1715-1724.

(2) Batten, S. R.; Champness, N. R.; Chen, X. M.; Garcia-Martinez, J.; Kitagawa, S.; Öhrström, L.; O’Keeffe, M.; Suh, M. P.; Reedijk, J. Coordination Polymers, Metal-Organic Frameworks and the Need for Terminology Guidelines. CrystEngComm 2012, 14 (9), 3001-3004.

(3) Kondo, M.; Yoshitomi, T.; Seki, K.; Matsuzaka, H.; Kitagawa, S. Three-Dimensional Framework with Channeling Cavities for Small Molecules: $\left\{\left[\mathrm{M} 2\left(4,4^{\prime}-\mathrm{Bpy}\right)_{3}\left(\mathrm{NO}_{3}\right)_{4}\right] \cdot \mathrm{XH}_{2} \mathrm{O}\right\} \mathrm{n}(\mathrm{M}=\mathrm{Co}, \mathrm{Ni}$, Zn). Angew. Chemie 1997, 36 (16), 1725-1727.

(4) Cheetham, A. K.; Férey, G.; Loiseau, T. Open-Framework Inorganic Materials. Angew. Chemie 1999, 38, 3268-3292.

(5) Hoskins, B. F.; Robson, R. Design and Construction of a New Class of Scaffolding-like Materials Comprising Infinite Polymeric Frameworks of 3D-Linked Molecular Rods. A Reappraisal of the $\mathrm{Zn}(\mathrm{CN}) 2$ and $\mathrm{Cd}(\mathrm{CN}) 2$ Structures and the Synthesis and Structure of the Diamond-Related Framework. J. Am. Chem. Soc. 1990, 112 (4), 1546-1554.

(6) Yaghi, O. M.; Li, H. Hydrothermal Synthesis of a Metal-Organic Framework Containing Large Rectangular Channels. J. Am. Chem. Soc. 1995, 117 (41), 10401-10402.

(7) Moosavi, S. M.; Nandy, A.; Jablonka, K. M.; Ongari, D.; Janet, J. P.; Boyd, P. G.; Lee, Y.; Smit, B.; Kulik, H. J. Understanding the Diversity of the Metal-Organic Framework Ecosystem. Nat. Commun. 2020, 11 (1), 4068.

(8) Lee, J.; Farha, O. K.; Roberts, J.; Scheidt, K. A.; Nguyen, S. T.; Hupp, J. T. Metal-Organic Framework Materials as Catalysts. Chem. Soc. Rev. 2009, 38 (5), 1450-1459.

(9) Otake, K. I.; Cui, Y.; Buru, C. T.; Li, Z.; Hupp, J. T.; Farha, O. K. Single-Atom-Based Vanadium Oxide Catalysts Supported on Metal-Organic Frameworks: Selective Alcohol Oxidation and 
Structure-Activity Relationship. J. Am. Chem. Soc. 2018, 140 (28), 8652-8656.

(10) Wang, C.; An, B.; Lin, W. Metal-Organic Frameworks in Solid-Gas Phase Catalysis. ACS Catal. 2019, 9 (1), 130-146.

(11) Yang, D.; Gates, B. C. Catalysis by Metal Organic Frameworks: Perspective and Suggestions for Future Research. ACS Catal. 2019, 9 (3), 1779-1798.

(12) Xue, D. X.; Belmabkhout, Y.; Shekhah, O.; Jiang, H.; Adil, K.; Cairns, A. J.; Eddaoudi, M. Tunable Rare Earth Fcu-MOF Platform: Access to Adsorption Kinetics Driven Gas/Vapor Separations via Pore Size Contraction. J. Am. Chem. Soc. 2015, 137 (15), 50345040.

(13) Mason, J. A.; Veenstra, M.; Long, J. R. Evaluating Metal-Organic Frameworks for Natural Gas Storage. Chem. Sci. 2014, 5 (1), $32-51$.

(14) Ma, S.; Zhou, H. C. A Metal-Organic Framework with Entatic Metal Centers Exhibiting High Gas Adsorption Affinity. J. Am. Chem. Soc. 2006, 128 (36), 11734-11735.

(15) Kreno, L. E.; Leong, K.; Farha, O. K.; Allendorf, M.; Van Duyne, R. P.; Hupp, J. T. Metal-Organic Framework Materials as Chemical Sensors. Chem. Rev. 2012, 112 (2), 1105-1125.

(16) Bauer, C. A.; Timofeeva, T. V.; Settersten, T. B.; Patterson, B. D.; Liu, V. H.; Simmons, B. A.; Allendorf, M. D. Influence of Connectivity and Porosity on Ligand-Based Luminescence in Zinc Metal-Organic Frameworks. J. Am. Chem. Soc. 2007, 129 (22), 7136-7144.

(17) Zhang, X.; Ballem, M. A.; Hu, Z. J.; Bergman, P.; Uvdal, K Nanoscale Light-Harvesting Metal-Organic Frameworks. Angew. Chemie - Int. Ed. 2011, 50 (25), 5729-5733.

(18) Yaghi, O. M.; O'Keeffe, M.; Ockwig, N. W.; Chae, H. K.; Eddaoudi, M.; Kim, J. Reticular Synthesis and the Design of New Materials. Nature 2003, 423 (6941), 705-714.

(19) Goesten, M. G.; Kapteijn, F.; Gascon, J. Fascinating Chemistry or Frustrating Unpredictability: Observations in Crystal Engineering of Metal-Organic Frameworks. CrystEngComm 2013, 15 (45), 9249-9257.

(20) Tanabe, K. K.; Cohen, S. M. Postsynthetic Modification of Metal-Organic Frameworks-a Progress Report. Chem. Soc. Rev. 2011, 40 (2), 498-519.

(21) Deria, P.; Mondloch, J. E.; Karagiaridi, O.; Bury, W.; Hupp, J. T.; Farha, O. K. Beyond Post-Synthesis Modification: Evolution of Metal-Organic Frameworks via Building Block Replacement. Chem. Soc. Rev. 2014, 43 (16), 5896-5912.

(22) Kalaj, M.; Cohen, S. M. Postsynthetic Modification: An Enabling Technology for the Advancement of Metal-Organic Frameworks. ACS Cent. Sci. 2020, 6 (7), 1046-1057.

(23) Grancha, T.; Ferrando-Soria, J.; Zhou, H. C.; Gascon, J.; Seoane, B.; Pasán, J.; Fabelo, O.; Julve, M.; Pardo, E. Postsynthetic Improvement of the Physical Properties in a Metal-Organic Framework through a Single Crystal to Single Crystal Transmetallation. Angew. Chemie - Int. Ed. 2015, 54 (22), 6521-6525.

(24) Wang, Z.; Cohen, S. M. Postsynthetic Covalent Modification of a Neutral Metal-Organic Framework. J. Am. Chem. Soc. 2007, 129 (41), 12368-12369.

(25) Karagiaridi, O.; Bury, W.; Mondloch, J. E.; Hupp, J. T.; Farha, 0. K. Solvent-Assisted Linker Exchange: An Alternative to the de Novo Synthesis of Unattainable Metal-Organic Frameworks. Angew. Chemie - Int. Ed. 2014, 53 (18), 4530-4540.

(26) Kim, M.; Cahill, J. F.; Su, Y.; Prather, K. A.; Cohen, S. M. Postsynthetic Ligand Exchange as a Route to Functionalization of "inert" Metal-Organic Frameworks. Chem. Sci. 2012, 3 (1), 126130.

(27) Smith, S. J. D.; Konstas, K.; Lau, C. H.; Gozukara, Y. M.; Easton, C. D.; Mulder, R. J.; Ladewig, B. P.; Hill, M. R. Post-Synthetic Annealing: Linker Self-Exchange in UiO-66 and Its Effect on Polymer-Metal Organic Framework Interaction. Cryst. Growth Des. 2017, 17 (8), 4384-4392.

(28) Dincă, M.; Long, J. R. High-Enthalpy Hydrogen Adsorption in Cation-Exchanged Variants of the Microporous Metal-Organic
Framework $\mathrm{Mn}_{3}\left[\left(\mathrm{Mn}_{4} \mathrm{Cl}\right)_{3}(\mathrm{BTT})_{8}\left(\mathrm{CH}_{3} \mathrm{OH}\right)_{10}\right]_{2}$. J. Am. Chem. Soc. 2007, 129 (36), 11172-11176.

(29) Lalonde, M.; Bury, W.; Karagiaridi, O.; Brown, Z.; Hupp, J. T.; Farha, O. K. Transmetalation: Routes to Metal Exchange within Metal-Organic Frameworks. J. Mater. Chem. A 2013, 1 (18), 54535468.

(30) Islamoglu, T.; Goswami, S.; Li, Z.; Howarth, A. J.; Farha, O. K.; Hupp, J. T. Postsynthetic Tuning of Metal-Organic Frameworks for Targeted Applications. Acc. Chem. Res. 2017, 50 (4), 805-813.

(31) Mondloch, J. E.; Bury, W.; Fairen-Jimenez, D.; Kwon, S.; Demarco, E. J.; Weston, M. H.; Sarjeant, A. A.; Nguyen, S. T.; Stair, P. C.; Snurr, R. Q.; Farha, O. K.; Hupp, J. T. Vapor-Phase Metalation by Atomic Layer Deposition in a Metal-Organic Framework. J. Am. Chem. Soc. 2013, 135 (28), 10294-10297.

(32) Liu, T. F.; Vermeulen, N. A.; Howarth, A. J.; Li, P.; Sarjeant, A. A.; Hupp, J. T.; Farha, O. K. Adding to the Arsenal of ZirconiumBased Metal-Organic Frameworks: The Topology as a Platform for Solvent-Assisted Metal Incorporation. Eur. J. Inorg. Chem. 2016, 2016 (27), 4349-4352.

(33) Yuan, S.; Chen, Y. P.; Qin, J.; Lu, W.; Wang, X.; Zhang, Q.; Bosch, M.; Liu, T. F.; Lian, X.; Zhou, H. C. Cooperative Cluster Metalation and Ligand Migration in Zirconium Metal-Organic Frameworks. Angew. Chemie - Int. Ed. 2015, 54 (49), 14696-14700.

(34) Mandal, S.; Natarajan, S.; Mani, P.; Pankajakshan, A. PostSynthetic Modification of Metal-Organic Frameworks Toward Applications. Adv. Funct. Mater. 2021, 31 (4), 2006291.

(35) Saraci, F.; Quezada-Novoa, V.; Donnarumma, P. R.; Howarth, A. J. Rare-Earth Metal-Organic Frameworks: From Structure to Applications. Chem. Soc. Rev. 2020, 49 (22), 7949-7977.

(36) Pagis, C.; Ferbinteanu, M.; Rothenberg, G.; Tanase, S. Lanthanide-Based Metal Organic Frameworks: Synthetic Strategies and Catalytic Applications. ACS Catal. 2016, 6, 6063-6072.

(37) Das, S.; Kim, H.; Kim, K. Metathesis in Single Crystal: Complete and Reversible Exchange of Metal Ions Constituting the Frameworks of Metal-Organic Frameworks. J. Am. Chem. Soc. 2009, 131 (11), 3814-3815.

(38) Seth, S.; Savitha, G.; Moorthy, J. N. Diverse Isostructural MOFs by Postsynthetic Metal Node Metathesis: Anionic-to-Cationic Framework Conversion, Luminescence and Separation of Dyes. J. Mater. Chem. A 2015, 3 (45), 22915-22922.

(39) Asha, K. S.; Bhattacharjee, R.; Mandal, S. Complete Transmetalation in a Metal-Organic Framework by Metal Ion Metathesis in a Single Crystal for Selective Sensing of Phosphate Ions in Aqueous Media. Angew. Chemie 2016, 128 (38), 11700-11704.

(40) Ding, W.; Zhao, L.; Yuan, X.; Zhang, L.; Chen, B.; Ju, Q.; Fang, Z. Multicolour Barcoding in One MOF Crystal through Rational Postsynthetic Transmetalation. J. Mater. Chem. C 2020, 8 (9), 3176-3182.

(41) Yang, Y.; Zhao, L.; Sun, M.; Wei, P.; Li, G.; Li, Y. Highly Sensitive Luminescent Detection toward Polytypic Antibiotics by a Water-Stable and White-Light-Emitting MOF-76 Derivative. Dye. Pigment. 2020, 180, 108444.

(42) Wang, P.; Ma, J. P.; Dong, Y. Bin; Huang, R. Q. Tunable Luminescent Lanthanide Coordination Polymers Based on Reversible Solid-State Ion-Exchange Monitored by Ion-Dependent Photoinduced Emission Spectra. J. Am. Chem. Soc. 2007, 129 (35), 1062010621.

(43) Lv, X. L.; Feng, L.; Xie, L. H.; He, T.; Wu, W.; Wang, K. Y.; Si, G.; Wang, B.; Li, J. R.; Zhou, H. C. Linker Desymmetrization: Access to a Series of Rare-Earth Tetracarboxylate Frameworks with EightConnected Hexanuclear Nodes. J. Am. Chem. Soc. 2021, 143 (7), 2784-2791.

(44) Wang, T. C.; Vermeulen, N. A.; Kim, I. S.; Martinson, A. B. F.; Fraser Stoddart, J.; Hupp, J. T.; Farha, O. K. Scalable Synthesis and Post-Modification of a Mesoporous Metal-Organic Framework Called NU-1000. Nat. Protoc. 2016, 11 (1), 149-162.

(45) Quezada-novoa, V.; Titi, H. M.; Sarjeant, A.; Howarth, A. Building a Shp: A New Rare-Earth Metal-Organic Framework and 
Its Application in a Catalytic Photo-Oxidation Reaction. ChemRxiv 2020, Preprint.

(46) Xue, D.-X.; Cairns, A. J.; Belmabkhout, Y.; Wojtas, L.; Liu, Y.; Alkordi, M.; Eddaoudi, M. Tunable Rare-Earth Fcu-MOFs: A Platform for Systematic Enhancement of $\mathrm{CO} 2$ Adsorption Energetics and Uptake. J. Am. Chem. Soc. 2013, 135, 7660-7667.

(47) Jiang, H.; Jia, J.; Shkurenko, A.; Chen, Z.; Adil, K.; Belmabkhout, Y.; Weselinski, L. J.; Assen, A. H.; Xue, D.-X.; O’Keefe, M.; Eddaoudi, M. Enriching the Reticular Chemistry Repertoire: Merged Nets Approach for the Rational Design of Intricate Mixed-Linker Metal-Organic Framework Platforms. J. Am. Chem. Soc. 2018, 140, 8858-8867.

(48) Zhang, L.; Yuan, S.; Feng, L.; Guo, B.; Qin, J.; Xu, B.; Lollar, C.; Sun, D.; Zhou, H. Pore-Environment Engineering with Multiple Metal Sites in Rare- Earth Porphyrinic Metal-Organic Frameworks. Angew. Chemie - Int. Ed. 2018, 57, 5095-5099.

(49) Wang, Y.; Feng, L.; Fan, W.; Wang, K.-Y.; Wang, X.; Wang, X.; Zhang, K.; Zhang, X.; Dai, F.; Sun, D.; Zhou, H.-C. Topology Exploration in Highly Connected Rare-Earth Metal-Organic Frameworks via Continuous Hindrance Control. J. Am. Chem. Soc. 2019, 141, 6967-6975.

(50) Prasad, T. K.; Hong, D. H.; Suh, M. P. High Gas Sorption and Metal-Ion Exchange of Microporous Metal-Organic Frameworks with Incorporated Imide Groups. Chem. - A Eur. J. 2010, 16, 14043-14050.

(51) Song, X.; Jeong, S.; Kim, D.; Lah, M. S. Transmetalations in Two Metal-Organic Frameworks with Different Framework
Flexibilities: Kinetics and Core-Shell Heterostructure. Cryst Growth Des. 2012, 14, 5753-5756.

(52) Pal, T. K.; De, D.; Senthilkumar, S.; Neogi, S.; Bharadwaj, P. K. A Partially Fluorinated, Water-Stable Cu(II)-MOF Derived via Transmetalation: Significant Gas Adsorption with High CO2 Selectivity and Catalysis of Biginelli Reactions. Inorg. Chem. 2016, 55, 7835-7842.

(53) Balestri, D.; Bassanetti, I.; Canossa, S.; Gazzurelli, C.; Bacchi, A.; Bracco, S.; Comotti, A.; Pelagatti, P. Changing the Dress to a MOF through Fluorination and Transmetalation. Structural and Gas-Sorption Effects. Cryst. Growth Des. 2018, 18, 6824-6832.

(54) Janicki, R.; Mondry, A.; Starynowicz, P. Carboxylates of Rare Earth Elements. Coord. Chem. Rev. 2017, 340, 98-133.

(55) Thommes, M.; Kaneko, K.; Neimark, A. V.; Olivier, J. P.; Rodriguez-Reinoso, F.; Rouquerol, J.; Sing, K. S. W. Physisorption of Gases, with Special Reference to the Evaluation of Surface Area and Pore Size Distribution (IUPAC Technical Report). Pure Appl. Chem. 2015, 87 (9-10), 1051-1069.

(56) Chen, Z.; Weselinski, L. J.; Adil, K.; Belmabkhout, Y.; Shkurenko, A.; Jiang, H.; Bhatt, P. M.; Guillerm, V.; Dauzon, E.; Xue, D.-X.; O'Keeffe, M.; Eddaoudi, M. Applying the Power of Reticular Chemistry to Finding the Missing Alb-MOF Platform Based on the $(6,12)$ Coordinated Edge-Transitive Net. J. Am. Chem. Soc. 2017, 139, $3265-3274$ 
SYNOPSIS TOC (Word Style "SN_Synopsis_TOC"). If you are submitting your paper to a journal that requires a synopsis graphic and/or synopsis paragraph, see the Instructions for Authors on the journal's homepage for a description of what needs to be provided and for the size requirements of the artwork. 